\title{
Heats of Hydration and Pozzolan Content of Portland-Pozzolan Cements
}

\author{
Edwin S. Newman and Lansing S. Wells
}

\begin{abstract}
Methods are described for the measurement of the approximate heat of solution in acid of portland-cement-pozzolan mixtures. Examples are given of the estimation of the heat of hydration of portland-pozzolan cements. Determinations of the amount of material undissolved in the calorimeter, as well as the heats of solution, were applied to the problem of determining the composition of mixtures of portland cement and pozzolan. Data are presented for the calculation of the heat capacity of the vacuum-flask calorimeter with amounts of hydrofluoric acid other than the 8-milliliter quantity used in measuring the heat of hydration of portland cement by the standard method.
\end{abstract}

\section{Introduction}

In recent years pozzolans have been widely used with portland cement because of their favorable effects on many of the properties of concrete. Many methods of test of cement or of concrete are not affected by the presence of the pozzolan, which contains a large percentage of silica. The measurement of the heat of hardening $[1,2]^{1}$ of a portlandpozzolan cement by the heat-of-solution procedure however, is less reliable than the measurement for ordinary portland cement because of the presence of material not readily soluble in acid. The heat-ofsolution method depends on the measurement of the heats of solution in acid of a sample of dry cement and of a corresponding sample of hardened paste. The difference between the two heats of solution is the heat of hardening of the cement paste. A mixture of nitric and hydrofluoric acids, in which nearly all portland cements will dissolve rapidly and completely, is used. Considerable portions of many pozzolans, however, are not readily soluble, and for even approximately complete solution far more time would be required than is desirable in the usual procedure for portland cement. The Bureau has occasionally measured the approximate heat of solution or hydration of pozzolan cements in a variety of investigations scattered over a period of nearly two decades. This paper presents the results of tests made by methods devised to reduce the effect of the difficultly soluble material.

In addition to the problem of measuring the heat of hydration of portland-pozzolan cements, there also exists, perhaps more urgently, the problem of determining the pozzolan content of such blends. In the course of the calorimetric measurements, it was observed that part of each pozzolan was undissolved. It was also observed that the heats of solution of the cement-pozzolan mixtures, as well as the percentage of undissolved material, were related to the pozzolan content. So that these data might not be lost, they have been included in this paper, and their application to the measurement of the pozzolan content of portland-pozzolan cements is discussed.

${ }^{1}$ Figure in brackets indicate literature references at the end of this paper.
Two calorimeters were used for this work: (1) an isothermal-jacket precision-type calorimeter, and (2) the vacuum-flask calorimeter required by the ASTM and the Federal Specification Board for the routine determination of the heat of hydration of portland cement $[1,2]$. The isothermal-jacket calorimeter is equipped with a controlled-temperature water bath, a platinum resistance thermometer, and electrical and time-measuring instruments for determining with high precision the temperature rise and the electrical energy of calibration. The vacuumflask calorimeter consists only of a vacuum flask, a stirrer driven by a synchronous motor, and a Beckmann thermometer. No attempt is made to surround it with a constant-temperature environment, and it is subject to lags and errors arising from changes in the laboratory temperature. Consequently, although it is much less expensive and easier to operate than the isothermal-jacket calorimeter, the vacuum-flask calorimeter is considerably less precise. Because of the difference in the operation of these instruments and in the application of their characteristics to the problem, they will be discussed separately.

\section{The Isothermal-Jacket Calorimeter}

The isothermal-jacket calorimeter described in other publications $[3,4]$ is capable of measuring the heat of solution of a $3-\mathrm{g}$ sample of a material completely soluble in $35 \mathrm{~min}$ with a precision (standard deviation of a single observation) of about 0.2 $\mathrm{cal} / \mathrm{g}$. However, the necessary corrections for thermal leakage, heats of stirring and evaporation, etc., increase progressively with the length of the solution period, and it is felt that $90 \mathrm{~min}$ is the longest solution period that should be used. For longer periods, the corrections become such a large portion of the measured temperature rise that they are applied with less confidence.

In the determination of a heat of solution, the apparatus is assembled, and the stirring motor is started and allowed to operate undisturbed until the temperature of the calorimeter is found to rise at a nearly uniform rate. The sample is introduced, and readings of the calorimeter temperature are taken until the rate of change has again become uniform. 
The two periods of constant rate are termed the initial and final rating periods, and the intervening time is known as the solution period. From observations of the temperature of the calorimeter and of the isothermal jacket during the rating periods, the thermal leakage constant and the heat of stirring and evaporation are calculated [5]. The corrections to be applied to the observed temperature change occuring during the solution period are calculated from these constants and from the calorimeter temperatures observed during that period.

If an experiment is performed with a completely soluble cement, and if observations are taken for an extended period, it will be found that soon after the introduction of the sample it is completely dissolved and that thereafter the calculated value of the heat of solution ceases to increase with longer solution periods. After the sample has dissolved completely, the calorimeter soon reaches a rate of temperature rise controlled by the heat of stirring and the thermal leakage to or from the surroundings. Corrections for these two factors during the solution period compensate for their effects, and, as a result, extending the solution period materially beyond the point at which solution is complete does not have any systematic effect upon the value obtained for the heat of solution of the sample. In fact, the best available criterion of the completion of the solution of the sample appears to be the repeated calculation of the heat of solution, using arbitrarily chosen solution periods of different lengths. In table 1 are listed heats of solution calculated in this manner for a sample of portland cement. It will be seen that the solution of the portland cement was completed in a relatively short time, since the calculated heat of solution became essentially constant after $30 \mathrm{~min}$.

If a similar experiment is performed with a pozzolan cement, the calculated value of the heat of solution continues to increase with increasing solu-

TABLE 1. Heats of solution of portland and portland-pozzolan cements

The heats of solution of 3-g samples (ignited weights) in $10 \mathrm{ml}$ of 48-percent $\mathrm{HF}$ plus sufficient $2.00 \mathrm{~N} \mathrm{HNO}_{3}$ to make $647.5 \mathrm{~g}$ of total acid were measured in a precision-type isothermal-jacket calorimeter [4]. Only two heat-of-solution experiments are represented. For each solution period indicated, all prior readings of calorimeter temperature are included in the calculations, the subsequent $10-\mathrm{min}$ period being taken as the final rating period.

\begin{tabular}{|c|c|c|}
\hline \multirow{2}{*}{$\begin{array}{l}\text { Duration of } \\
\text { solution } \\
\text { period }\end{array}$} & \multicolumn{2}{|c|}{ Calculated heat of solution } \\
\hline & $\begin{array}{l}\text { Portland } \\
\text { cement }\end{array}$ & $\begin{array}{l}\text { Portland- } \\
\text { pozzolan } \\
\text { cement }\end{array}$ \\
\hline $\begin{array}{l}\min \\
10 \\
11 \\
12 \\
13 \\
14 \\
15 \\
20 \\
25 \\
30 \\
35 \\
40 \\
45 \\
55 \\
65 \\
75 \\
80\end{array}$ & $\begin{array}{r}c a l / g \\
588.6 \\
589.4 \\
590.3 \\
591.1 \\
592.0 \\
592.6 \\
594.8 \\
596.4 \\
597.6 \\
598.1 \\
598.0 \\
598.2 \\
597.9 \\
- \\
-\end{array}$ & 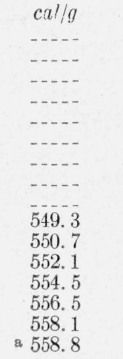 \\
\hline
\end{tabular}

a Undissolved at end of the experiment, 6.7 percent by weight. tion period because the difficultly soluble material continues slowly to dissolve. This condition is illustrated by the values given in table 1 for the heat of solution of a pozzolan cement. The calculated value was still increasing after a solution period of 75 min. It is impracticable to determine the total heat of solution of a cement that is still incompletely dissolved after such a long time.

\subsection{Heats of Hydration of Portland-Pozzolan Cements}

When a pozzolan cement is dissolved in the calorimeter, the greater part of the heat of solution is evolved in a relatively short time (see table 1). Since the hydrated pozzolan cement behaves similarly, an approximate value for the heat of hydration may be obtained without waiting for the complete solution of the sample. In table 2 are shown the heats of partial solution of several portland-pozzolan cements calculated for solution periods of increasing lengths. The values calculated for the hydrated pastes for similar periods are also shown. All these values are based on the total weight of the sample, without regard to the amount of material undissolved. The values in table 2 are (except for the last sample) each the average of two determinations. In no case did the two values differ by more than 4 $\mathrm{cal} / \mathrm{g}$, and in most cases the agreement was much better.

TABLE 2. Heats of partial solution and heats of hydration of portland-pozzolan cements Heats of solution of 3 -g samples (ignited weights) were determined in $10 \mathrm{ml}$ of
48-percent $\mathrm{HF}$ plus sufficient $2.00 \mathrm{NHNO}_{3}$ to make $647.5 \mathrm{~g}$ of total acid in a pre48-percent $\mathrm{HF}$ plus sufficient $2.00 \mathrm{NHNO}_{3}$ to make $647.5 \mathrm{~g}$ of total acid in a pre-
cision-type isothermal-jacket calorimeter [4]. Each value is the average of 2 determinations differing by not more than $4 \mathrm{cal} / \mathrm{g}$.

\begin{tabular}{|c|c|c|c|c|c|c|}
\hline \multirow{2}{*}{ Cement } & \multirow{2}{*}{$\begin{array}{l}\text { Solution } \\
\text { period }\end{array}$} & \multicolumn{3}{|c|}{ Heats of solution } & \multicolumn{2}{|c|}{ Heats of hydration } \\
\hline & & $\begin{array}{l}\text { Dry ce- } \\
\text { ment }\end{array}$ & $\begin{array}{l}\text { 7-day } \\
\text { paste }\end{array}$ & $\begin{array}{l}\text { 28-day } \\
\text { paste }\end{array}$ & 7-day & 28-day \\
\hline 3 & $\begin{array}{r}\min \\
25 \\
30 \\
35 \\
25 \\
30 \\
35 \\
25 \\
30 \\
35 \\
25 \\
30 \\
35 \\
25 \\
30 \\
35 \\
45 \\
55 \\
25 \\
30 \\
35 \\
45 \\
55\end{array}$ & \begin{tabular}{l} 
cal/g \\
527.4 \\
528.3 \\
529.2 \\
531.8 \\
533.8 \\
535.4 \\
582.8 \\
584.6 \\
585.9 \\
595.8 \\
596.0 \\
595.7 \\
546.1 \\
548.0 \\
549.5 \\
552.3 \\
554.7 \\
\hdashline.- \\
$-\cdots$ \\
$-\cdots$ \\
..--
\end{tabular} & $\begin{array}{l}c a l / g \\
464.9 \\
465.9 \\
466.6 \\
469.9 \\
471.7 \\
474.3 \\
504.9 \\
506.4 \\
507.3 \\
544.1 \\
-. .- \\
487.7 \\
489.4 \\
491.1 \\
493.8 \\
497.0 \\
-. .- \\
-. .- \\
-. .-\end{array}$ & $\begin{array}{l}\text { cal/g } \\
444.0 \\
445.0 \\
446.0 \\
455.0 \\
457.0 \\
458.6 \\
486.6 \\
488.4 \\
490.0 \\
526.2 \\
526.1 \\
526.0 \\
473.4 \\
475.0 \\
476.6 \\
477.0 \\
478.2 \\
\text { a } 473.1 \\
\text { a } 474.8 \\
\text { a } 476.2 \\
\text { a } 479.0 \\
\text { a } 480.0\end{array}$ & 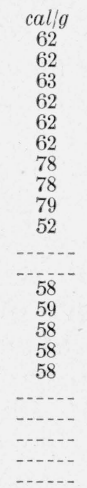 & $\begin{array}{l}c a l / g \\
83 \\
83 \\
83 \\
77 \\
77 \\
77 \\
96 \\
96 \\
96 \\
70 \\
70 \\
70 \\
73 \\
73 \\
73 \\
75 \\
76 \\
\text { a } 73 \\
\text { a } 73 \\
\text { a } 73 \\
\text { a } 73 \\
\text { a } 75\end{array}$ \\
\hline
\end{tabular}

a $\mathrm{R}$ ssults of 1 determination only. Values obtaiued at $30,35,45$, and $55 \mathrm{~min}$ wer 3 calculated from the same determinations as the 25 -min values, using timetemparature data tanen after $25 \mathrm{~min}$.

In table 3 are given the amounts of material undissolved at the end of the calorimetric experiments of table 2. The finding of more undissolved material remaining from the hydrated pastes than from the dry cements: was unexpected. The hydration 
reactions would be expected to render soluble in the acid mixture some part of the previously insoluble portion of the pozzolan. Similar behavior has been noted in other cases, although some reversals have been observed.

In table 2 the heats of hydration are shown as the differences between the heats of partial solution of the dry cement and of the hydrated pastes. Although, except for sample 4 , the heats of solution increase with increasing solution period, the heats of hydration do not so change. For these heats of hydration to be accurate, it is necessary to assume that any systematic errors are the same in the determinations of the heats of partial solution of the dry cements, and of the hydrates. Although this assumption may not be true from the standpoint of precise calorimetry, the error in the heat of hydration is probably small enough for the satisfactory testing of portland-pozzolan cement and must be accepted for the present in the absence of a more satisfactory method of test.

\section{TABLE 3. Material undissolved in the calorimeter}

Percentage of 3-g sample (ignited weight) of cement or cement paste undissolved in acid charge of $10 \mathrm{ml}$ of $\mathrm{HF}$ plus sufficient $2.00 \mathrm{~N} \mathrm{HNO}_{3}$ to make $647.5 \mathrm{~g}$ of total acid. Each value is the average of 2 determinations.

\begin{tabular}{|c|c|c|c|}
\hline Cement & Sample & $\begin{array}{l}\text { Undissolved } \\
\text { material }\end{array}$ & $\begin{array}{l}\text { Time in con- } \\
\text { tact with } \\
\text { acid mixture }\end{array}$ \\
\hline $\begin{array}{l}1 \ldots \\
2 \ldots \\
3 \ldots \\
4 \ldots\end{array}$ & $\begin{array}{l}\left\{\begin{array}{l}\text { Dry } \\
7 \text {-day paste } \\
\text { 28-day paste }\end{array}\right. \\
\left\{\begin{array}{l}\text { Dry } \\
\text { 7-day paste } 28 \text { day paste }\end{array}\right. \\
\text { 7ry day paste- } \\
\text { 28-day paste }\end{array}$ & $\begin{array}{r}\text { Percent } \\
9.2 \\
\text { a } 9.5 \\
9.9 \\
8.0 \\
8.3 \\
8.8 \\
2.9 \\
3.0 \\
3.8 \\
0.4 \\
.5 \\
.5 \\
7.0 \\
7.8 \\
8.0\end{array}$ & $\begin{array}{c}\text { Min } \\
43 \\
43 \\
48 \\
43 \\
51 \\
48 \\
43 \\
40 \\
43 \\
50 \\
31 \\
42 \\
85 \\
65 \\
58\end{array}$ \\
\hline
\end{tabular}

a One determination only.

The departure of the heat of partial solution of a portland-pozzolan cement from the value for complete solution arises from two sources, both caused by the difficulty of dissolving the pozzolan. The sample does not completely dissolve, and therefore the pozzolan does not contribute its entire heat of solution. (Portland cement is assumed to dissolve completely and usually does so.) The slow dissolving of the pozzolan during the final "rating period" continues to liberate heat, and thus slightly incorrect values are obtained for the heat of stirring and the coefficient of thermal leakage. If the pozzolan dissolves to the same extent and at the same rate for both the dry cement and the hydrated pastes, the systematic errors in the heats of partial solution disappear when the heat of hydration is calculated. Some idea of the possible effect of undissolved material may be obtained by noting that the maximum difference in undissolved material for dry cement and 28 -day hydrated paste in table 2 is 1.0 percent. If it is assumed that the heat of partial solution of the paste is therefore 1.0 percent, or 4.8 calories, low, the resulting error in the heat of hydration would be $5 \mathrm{cal} / \mathrm{g}$. It is doubtful if this large an error is caused because the heat of solution of undissolved pozzolan (see table 4) may be considerably less than the approximately $520 \mathrm{cal} / \mathrm{g}$ of a hydrated portlandcement paste.

\subsection{Heats of Solution and Undissolved Residues of Cement-Pozzolan Mixtures}

The heats of partial solution were determined for several finely ground pozzolans ${ }^{2}$ and for blends of these with finely ground portland-cement clinker. The samples were prepared by placing weighed amounts of the finely ground components in a laboratory ball mill with a few wooden balls and mixing for $2 \mathrm{hr}$. After the determinations of the heat of partial solution, the calorimeter acid was filtered and the residue of insoluble material was ignited, and weighed.

The values of the heat of solution are given in table 4 and are plotted in figure 1. The undissolved residue in the calorimeter, expressed as the percentage by weight of the sample, is given in table 5 and plotted in figure 2. It will be seen that a relatively constant proportion of the pozzolan remained undissolved at the end of the experiments, although the ratios of pozzolan to calorimeter acid differed rather widely. The experimental points fall closely about

TABLE 4. Heats of solution of portland-cement-pozzolan mixtures

Heats of solution of $3-\mathrm{g}$ samples (ignited weights) were determined in 10-ml of 48 -percent $\mathrm{HF}$ plus sufficient $2.00 \mathrm{~N} \mathrm{HNO}$ to make $647.5 \mathrm{~g}$ of total acid in a precision-type isothermal-jacket calorimeter [4]. Time of contact, $30 \mathrm{~min}$.

\begin{tabular}{|c|c|c|c|c|c|}
\hline \multirow{2}{*}{$\begin{array}{l}\text { Pozzolan } \\
\text { content } \\
\text { of mixture }\end{array}$} & \multicolumn{5}{|c|}{ Pozzolan } \\
\hline & A & B & $\mathrm{C}$ & $\mathrm{D}$ & $\mathrm{E}$ \\
\hline $\begin{array}{c}\text { Percent } \\
0 \\
20 \\
25 \\
30 \\
33 \\
35 \\
100\end{array}$ & $\begin{array}{c}\begin{array}{c}\text { cal/g } \\
601.6\end{array} \\
608.4 \\
621.2\end{array}$ & $\begin{array}{l}\mathrm{cal} / \mathrm{g} \\
601.6 \\
560.9 \\
551.6 \\
539.5 \\
538.3 \\
393.0\end{array}$ & $\begin{array}{l}\text { cal/g } \\
601.6 \\
541.1 \\
525.6 \\
511.5 \\
301.5\end{array}$ & $\begin{array}{c}\mathrm{cal} / \mathrm{g} \\
601.6 \\
535.0 \\
502.2 \\
269.9\end{array}$ & $\begin{array}{c}\mathrm{cal} / \mathrm{g} \\
601.6 \\
520.0 \\
485.3 \\
253.5\end{array}$ \\
\hline
\end{tabular}

TABLE 5. Solubility of portland-cement-pozzolan mixtures in acid

Undissolved portion of portland-cement-pozzolan mixtures, shown in table 4, after 30 -min contact with a mixture of $10 \mathrm{ml}$ of 48 -percent $\mathrm{HF}$ plus sufficient 2.00 $\mathrm{NHNO}_{3}$ to make $647.5 \mathrm{~g}$ of total acid.

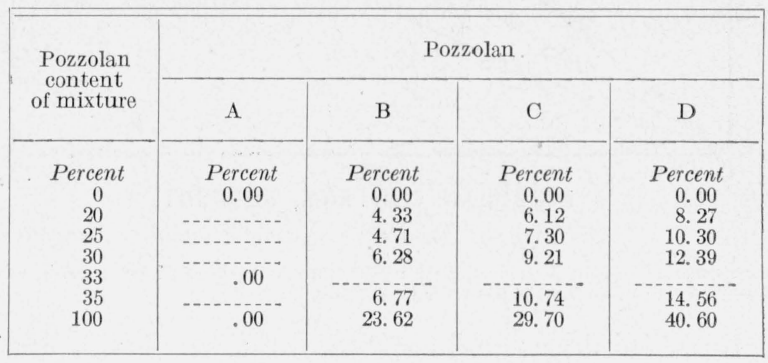

${ }^{2}$ Details of the constitution and properties of the pozzolans unfortunately are not now obtainable. Sample A, tables 4 and 5 and figures 1 and 2 , was a blastfurnace slag; B was a burned shale; $\mathrm{C}$ and $\mathrm{D}$ are identified as Pennsylvania pozzolans; and $\mathrm{E}$ as a California pozzolan. Before mixing, the clinker and the pozzolans were ground to finenesses now unknown but comparable to portland cement. 


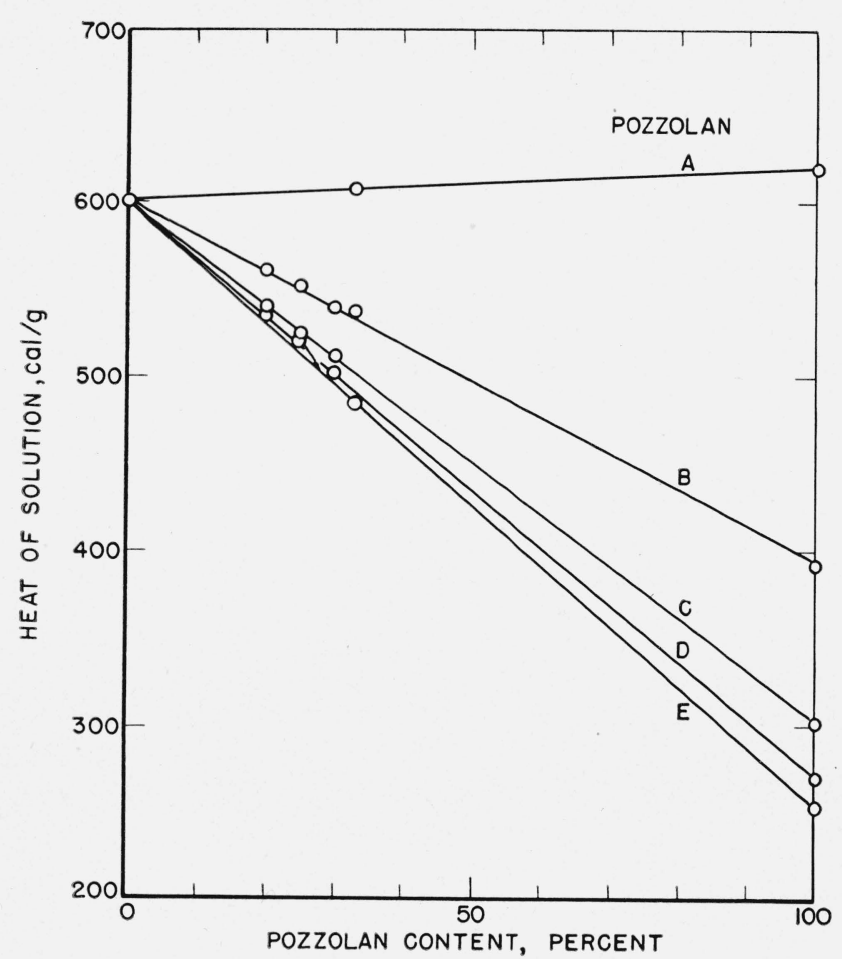

FIgURE 1. Heats of solution of portland cement-pozzolan mixtures.

The heats of solution were determined in a 647.5 -g mixture of $10 \mathrm{ml}$ of 48 -percent $\mathrm{HF}$ and $2.00 \mathrm{~N} \mathrm{HNO}_{3}$ in a precision-type isothermal-jacket calorimeter. Time of contact with acid, $30 \mathrm{~min}$

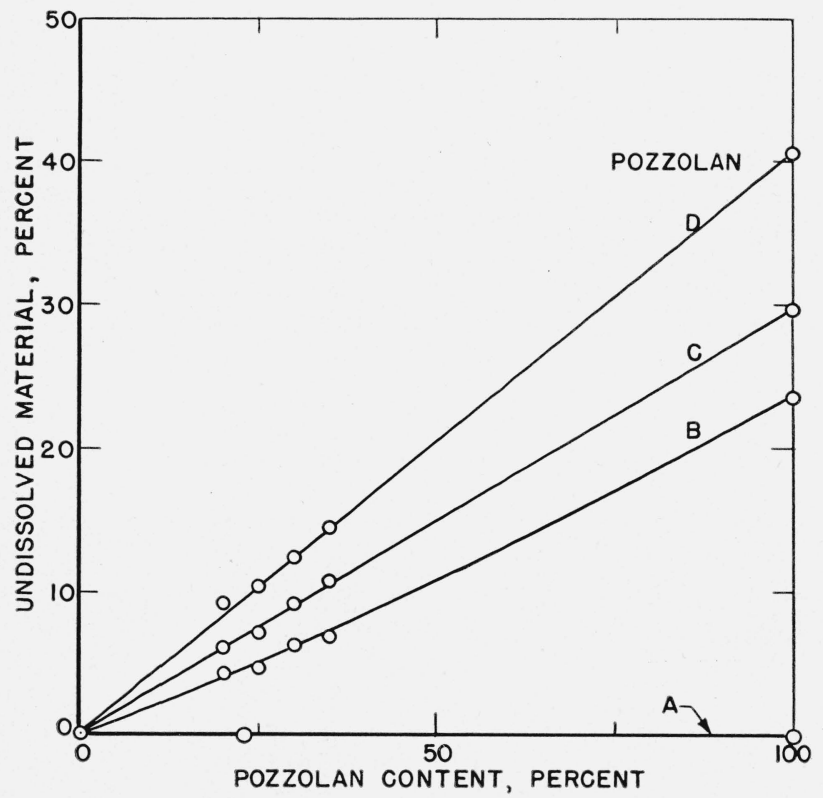

FIGURE 2. Solubility of portland cement-pozzolan mixtures.

Percentage of material undissolved by 30 -minute contact of 3 -g sample with 647.5 -g mixtures of $10 \mathrm{ml}$ of 48 -percent $\mathrm{HF}$ and $2.00 \mathrm{~N} \mathrm{HNO}_{3}$.

the lines joining the heats of solution of the components of the mixtures and indicate that the experimental values of the heat of solution agree well with the values calculated from the proportions of cement and pozzolan.

\section{The Vacuum-flask Calorimeter}

To determine the heat of partial solution of a pozzolan cement with the vacuum-flask calorimeter, a modification of the standard $[1,2]$ procedure for portland cement is useful. The environment of the calorimeter is not sufficiently well defined, nor is its temperature measured with sufficient accuracy, to permit the use of long solution periods. However, by assuming that the temperature of the environment (the room temperature) remains constant, and that the thermal leakage remains at the average value determined during measurements made with portland cement, one of the two rating periods ordinarily necessary to calculate the corrected temperature rise can be eliminated. It is convenient in working with pozzolan cements to omit the final rating period. Then at some arbitrarily chosen time, such as $60 \mathrm{~min}$ after the introduction of the sample, the solution period can be considered ended and the determination stopped. It must be emphasized that even in the standard procedure $[1,2]$ the room temperature is assumed constant. The equation for the corrected temperature rise $R[2, \mathrm{p} .51]$ becomes by this method

$$
R=\theta_{60}-\theta_{i}-V_{a} T_{x}+K\left(\theta_{x} T_{x}-\theta_{a} T_{x}\right),
$$

where

$\theta_{i}, \theta_{60}=$ temperature of the calorimeter at the beginning and end, respectively, of the solution period.

$V_{a}=$ the average temperature rise per 5-min interval during the initial rating period;

$T_{x}=$ the number of 5 -min intervals in the solution period, here arbitrarily taken 12 ;

$\theta_{a}=$ the average calorimeter temperature during the initial rating period;

$\theta_{x}=$ the average calorimeter temperature during the solution period, $\left(\theta_{x} T_{x}\right.$ is the integral of the time-temperature curve during the solution period); and,

$K=$ the thermal leakage coefficient, 0.0055 $(5-\min )^{-1}$ in the present work.

These symbols are the same as in the published specifications $[1,2]$. The corrected temperature rise, $R$, is multiplied by the heat capacity of the calorimeter, and the product divided by the ignited weight of the sample is the heat of solution. To increase the precision of the determination of $V_{a}$, the initial rating period is extended over a 20 -min period. This procedure is less precise than the normal determination of the heat of solution of a portland cement, but by its use an approximate value of the heat of partial solution of a pozzolan cement can be obtained.

\subsection{Heat of Solution and Pozzolan \\ a. Content of Cement-Pozzolan Mixtures}

The work reported in the first part of this paper seemed to show linear relations between the heats of partial solution of cement-pozzolan mixtures and 
the percentages of pozzolan present. From such a relation, the composition of a mixture might be calculated from determinations of the heats of solution of the mixture and its two components. This calculation would be useful if the heats of solution of the two components were sufficiently different. To test the method, determinations were made of the heats of solution of a series of mixtures of cement and pozzolan. Two unknown mixtures were supplied by a cement manufacturer, together with samples of the cement and the pozzolan with which they had been prepared. Known mixtures were prepared at the Bureau and their heats of solution determined by means of the vacuum-flask calorimeter The heats of solution of the cement and of the pozzolan were also determined. The normal amount, $8 \mathrm{ml}$, of hydrofluoric acid was used, and each determination was arbitrarily ended $60 \mathrm{~min}$ after the introduction of the sample. The undissolved material remaining in the calorimeter at the end of each determination was recovered on a filter, ignited, and weighed. The heats of partial solution were calculated by the procedure already described.

The data obtained are given in table 6 and shown in figure 3 . The relation between the percentage pozzolan and the heat of partial solution of the mixture is not linear. The equation of a line representing these data, chosen by the method of least squares, is

$$
H=607.8-0.939 P-0.00344 P^{2},
$$

where $P$ is the percentage of pozzolan, and $H$ is the heat of partial solution of the mixture. From the equation and the average values of the heat of solution of the unknown samples of 592.5 and 581.3

\section{TABLE 6. Heats of solution of cement-pozzolan mixtures in acid}

The heats of solution were measured in a vacuum-flask calorimeter $[1,2]$ Determinations were ended arbitrarily after 60 -min contact between the mixture and the acid charge of $8 \mathrm{ml}$ of 48-percent $\mathrm{HF}$ and sufficient $2.00 \mathrm{~N} \mathrm{HNO}_{3}$ to make a total weight of $425 \mathrm{~g}$. Thermal leakage of calorimeter was taken as its average of $0.0055(5-\mathrm{min})^{-1}$, and the final rating period was omitted.

\begin{tabular}{|c|c|c|c|}
\hline Sample & $\begin{array}{l}\text { Pozzolan } \\
\text { content }\end{array}$ & $\begin{array}{l}\text { Heat of } \\
\text { solution }\end{array}$ & $\begin{array}{l}\text { Undis- } \\
\text { solved } \\
\text { residue }\end{array}$ \\
\hline $\begin{array}{l}12 \\
13 \\
14 \\
15 \\
16 \\
17 \text { a } \\
18 \mathrm{~b}\end{array}$ & $\left\{\begin{array}{c}\text { Percent } \\
0 \\
0 \\
0 \\
0 \\
100 \\
100 \\
100 \\
20 \\
20 \\
40 \\
40 \\
60 \\
60 \\
80 \\
80\end{array}\right.$ & $\begin{array}{r}c a l / g \\
607.4 \\
607.2 \\
612.4 \\
607.9 \\
481.5 \\
475.0 \\
478.0 \\
582.8 \\
587.2 \\
564.4 \\
562.8 \\
542.4 \\
537.8 \\
510.5 \\
517.5 \\
592.3 \\
592.7 \\
569.8 \\
578.6 \\
580.0 \\
585.1 \\
581.4\end{array}$ & $\begin{array}{c}\text { Percent } \\
0 \\
0 \\
0 \\
0 \\
18.34 \\
20.56 \\
18.75 \\
2.80 \\
3.11 \\
5.99 \\
6.55 \\
9.85 \\
10.19 \\
13.91 \\
14.38 \\
1.55 \\
1.77 \\
3.51 \\
3.91 \\
3.88 \\
3.98 \\
3.83\end{array}$ \\
\hline
\end{tabular}

a Stated by the manufacturer to contain 10.5 percent of pozzolan.

b Stated by the manufacturer to contain 25.5 percent of pozzolan.

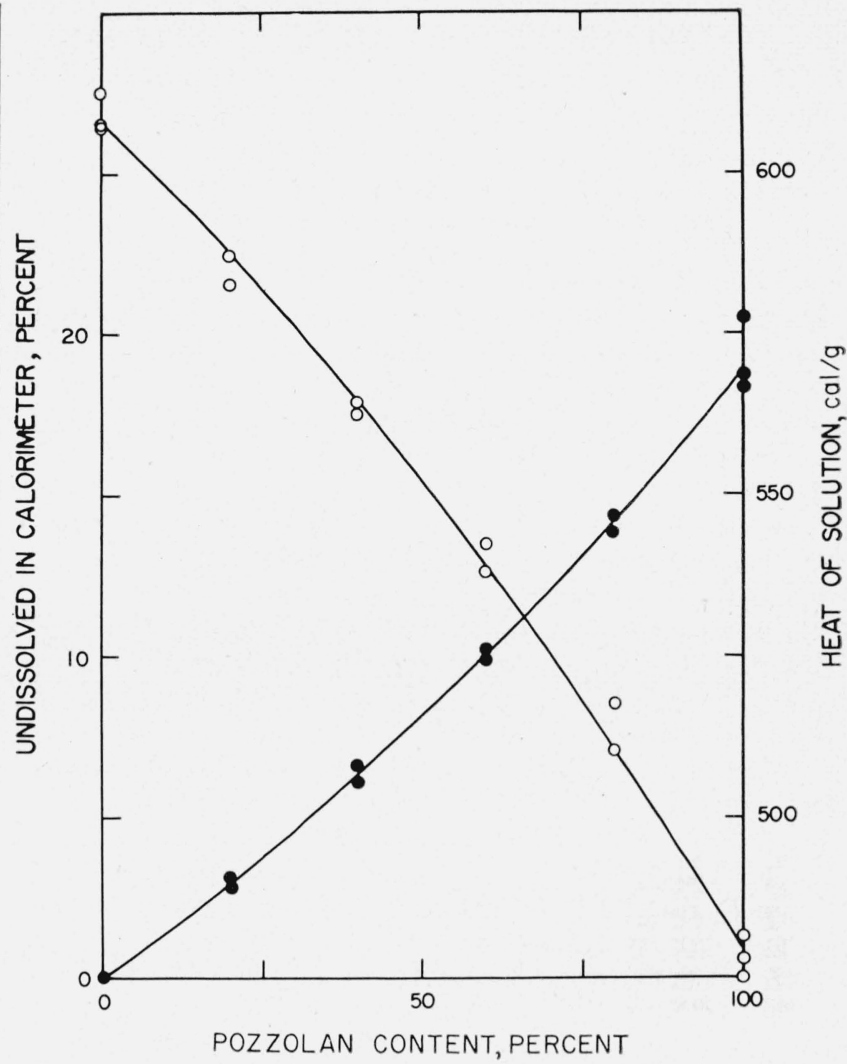

FIGURE 3. Heats of solution and undissolved residues of portland cement-pozzolan mixtures in the vacuum-flask calorimeter.

Determinations ended after 60-minute contact between $3-\mathrm{g}$ samples and acid charges of $8 \mathrm{ml}$ of 48-percent $\mathrm{HF}$ and sufficient $2.00 \mathrm{NHNO}_{3}$ to make a total weight of charge of $425 \mathrm{~g}$. Open circles, heat of solution; closed circles, undissolved residue.

$\mathrm{cal} / \mathrm{g}$, respectively, for samples 7 and 8 , table 6 , the amount of pozzolan in the two samples was calculated to be 15.2 and 25.8 percent, respectively. The precision of these data is such that the estimated value of the standard deviation is about $\pm 2.9 \mathrm{cal} / \mathrm{g}$, which corresponds to about \pm 3.1 percent of pozzolan in the cement-pozzolan mixture. The actual compositions of the two unknown mixtures were subsequently given by the manufacturer as 10.5 and 25.5 percent of pozzolan, respectively.

In view of the good agreement between the observed and calculated heats of solution of the known mixtures of cement and pozzolan, it was rather surprising to find such a wide difference between the value of 10.5 percent of pozzolan given for one mixture and the $15.2 \pm 3.1$ percent determined from the heat of solution. For the other unknown sample the agreement is excellent between the 25.5 percent given and the $25.8 \pm 3.1$ percent of pozzolan found.

\subsection{Undissolved Residues of Cement-Pozzolan Mixtures}

The determination of the undissolved residue appeared to give a better and simpler method of determining the percentage of pozzolan in a cement-pozzolan mixture. The percentages of undissolved residue obtained in the experiments described above are 
given in table 6 and are shown in figure 3 . The equation of the line fitted to these data by the method of least squares is

$$
U=0.108+0.1268 P+0.000636 P^{2},
$$

where $P$ is the percentage pozzolan in the mixture, and $U$ is the percentage undissolved material. Values of the pozzolan content of the two "unknown" samples calculated from the above equation were $11.6 \pm 0.8$ and $25.9 \pm 1.0$ percent, respectively. These values agree better with the given compositions of the unknown samples than do the values calculated from the heats of solution. The precision is better also, since the standard deviation of the percentage calculated from the heat of solution is three times that determined from the insoluble material.

The determination of undissolved material is much simpler than the determination of the heat of solution, as no calorimeter is needed. Plastic beakers can be used for reaction vessels with a stirring machine, such as is now commonly used in cement laboratories for the analytical determination of $\mathrm{MgO}$ with 8-hydroxyquinoline. The practicability of the determination of the pozzolan content of a mixture by either method depends on the percentage of the pozzolan dissolved by the acid in a given time interval. The rate of solution will vary with the surface area and with the type of pozzolan, and a curve must be determined for each variety of pozzolan and of cement. If solution is complete, the insoluble-material method cannot be used, but the heat-of-solution method will be improved in

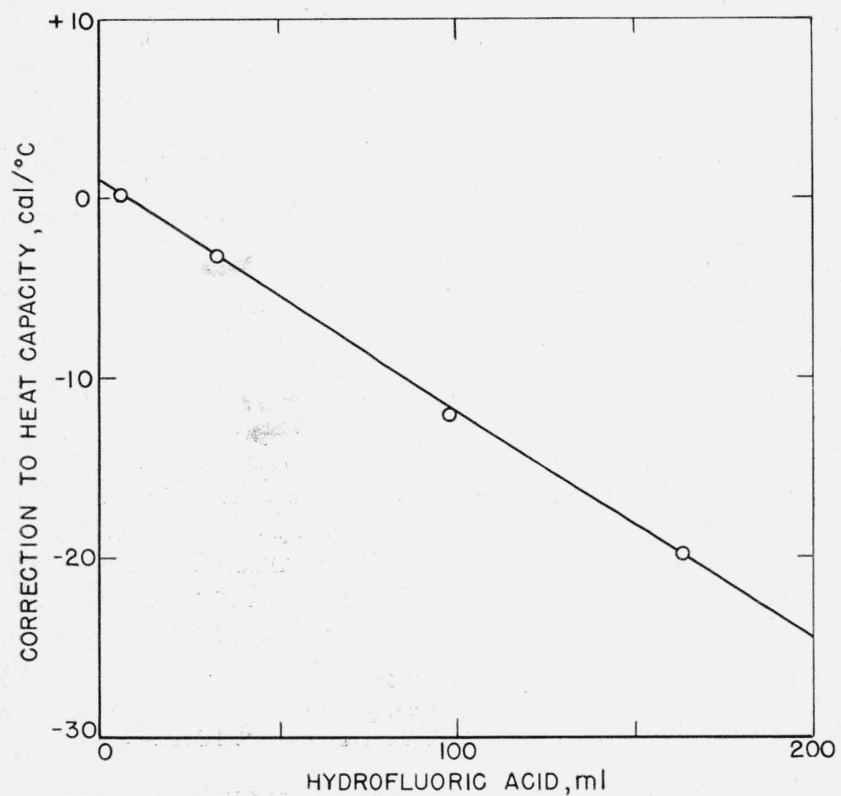

FIGURE 4. Heat-capacity correction for vacuum-flask calorimeter

Correction to be added to value obtained by the standard method with $\mathrm{ZnO}$, using $8 \mathrm{ml}$ of 48-percent $\mathrm{HF}$ and sufficient $2.00 \mathrm{~N} \mathrm{HNO}_{3}$ to make $425 \mathrm{~g}$ of acid. For use only with $425 \mathrm{~g}$ of total acid consisting of $2.00 \mathrm{~N} \mathrm{HNO}_{3}$ and indicated amount of hydrofluorie acid. The equation of the line is $C=1.02-0.127 \mathrm{M}$, where $C$ is the correction to be added, and $M$ is the number of milliliters of 48 percent $\mathrm{HF}$ in the 425 -g aeid charge. accuracy because of the improvement in the accuracy of the calorimetric determination.

\subsection{Heat-Capacity Corrections}

For some pozzolans it may be desirable to use more than $8 \mathrm{ml}$ of hydrofluoric acid in the calorimeter in order to expedite the dissolving of the sample. Such a change will alter the heat capacity of the calorimeter. Normally, the heat capacity is determined by dissolving a standard substance, zinc oxide, in the $425-\mathrm{g}$ charge of $2.00 \mathrm{~N} \mathrm{HNO}_{3}$ containing $8 \mathrm{ml}$ of 48-percent $\mathrm{HF}$. For this purpose the heat of solution of zinc oxide in such a mixture has been carefully determined, and the value has been published in the specifications. However, data are not available for other mixtures of nitric and hydrofluoric acid so that the heat capacity of the calorimeter containing other amounts of $\mathrm{HF}$ cannot be determined by the specification method. The heat capacity can be calculated, however, from the change in the heat capacity of the liquid contents of the calorimeter, since the heat capacity of the glass, plastic, and metal parts are not affected by a change in the concentration of hydrofluoric acid. From heat-capacity data obtained with the precision calorimeter, the correction to be made to the heat capacity determined with the solution containing 8 $\mathrm{ml}$ of $\mathrm{HF}$ was calculated over a range of concentration of $\mathrm{HF}$ from 0 to $0.47 \mathrm{ml}$ of 48 -percent $\mathrm{HF}$ solution per gram of total acid $\left(\mathrm{HF}+2.00 \mathrm{~N} \mathrm{HNO}_{3}\right)$. The maximum concentration corresponds to the use of $200 \mathrm{ml}$ of $\mathrm{HF}$ in the 425-g calorimeter charge. The correction to be applied can be estimated from figure 4 and may be calculated from the equation $C=1.02-0.127 M$, where $C$ is the correction in calories per degree Celsius (centigrade) and $M$ is the milliliters of 48 -percent $\mathrm{HF}$ in $425 \mathrm{~g}$ of total acid.

The authors acknowledge their indebtedness to J. Arthur Swenson, formerly of the National Bureau of Standards, who determined the heats of solution of the cement-pozzolan mixtures with the precision calorimeter.

\section{References}

[1] Federal Specification SS-C-158b for Cements, hydraulic; general specifications (Methods for sampling, inspection, and testing) (May 20, 1946).

[2] Standard Method of test for heat of hydration of portland cement. American Society for Testing Materials, Designation C-186-47. (October 15, 1947).

[3] Edwin S. Newman and Lansing S. Wells, Heats of hydration and transition of calcium sulfate. J. Research NBS 20 , 825 (1938) RP1107.

[4] Leo Shartsis and Edwin S. Newman, Some energy relations in the systems $\mathrm{PbO}-\mathrm{B}_{2} \mathrm{O}_{3}$ and $\mathrm{Pb}-\mathrm{SiO}_{2}$. J. Research NBS 40, 471 (1948) RP1893.

[5] Walter P. White, The modern calorimeter. (The Chemical Catalog Co., New York, N. Y., 1928).

Washington, April 7, 1952. 